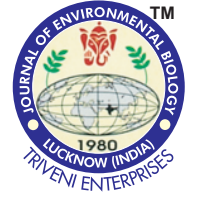

\title{
Evaluation of solar energy by the general directorate of forest-village relations in the south west region of Anatolia
}

\section{Authors Info}

\section{U. COŞGUN}

Department of Forestry Engineering, Faculty of Forestry, Karabük University Karabuk, 78100, Turkey

*Corresponding Author Email : ufukcoşgun@karabuk.edu.tr

Key words

Forest villages,

Fuel wood

Solar water heating system

Publication Info

Paper received : 20.06.2016

Revised received : 20.05.2017

Accepted : 28.06.2017

\section{Abstract}

Aim :This study investigated the results of the survey carried out on solar energy systems in 2005, by the General Directorate of Forest-Village Relations (GDoFVA), with the objective of minimizing the consumption of firewood to obtain hot water.

Methodology : Data concerning the impact of solar energy systems on forest villages was obtained by means of a face-to-face survey and 629 questionnaires, conducted in 152 forest villages of Antalya, Burdur and Isparta provinces, located in the Western Mediterranean Region of Turkey. Frequency distributions and the percentage of statements were assessed using Chi-square and simple correlation analysis methods.

Results : The General Directorate of Forest-Village Relations, (GDoFVA), stated that use of solar energy systems, decreased the consumption of firewood by $60-70 \%$ in forest villages. In contrast, the results of the current study showed that forest villages of the Western Mediterranean Region had saved firewood in the region of $20-30 \%$ by using SES.

Interpretation : The average consumption of firewood per household in the forest villages of the Western Mediterranean Region is 11.74 stere per annum. If the saving of firewood was found to be $30 \%$, then the average amount of firewood saved per household was 3.2 stere per annum. The saving of firewood using solar energy systems was estimated approximately $336,042 \mathrm{TL}$ annually, according to the market prices for households. On the other hand, the solar energy systems practices do suggest support that is successful social enhance practice and economic additive. The practice has ensured a significant social development in forest villagers.

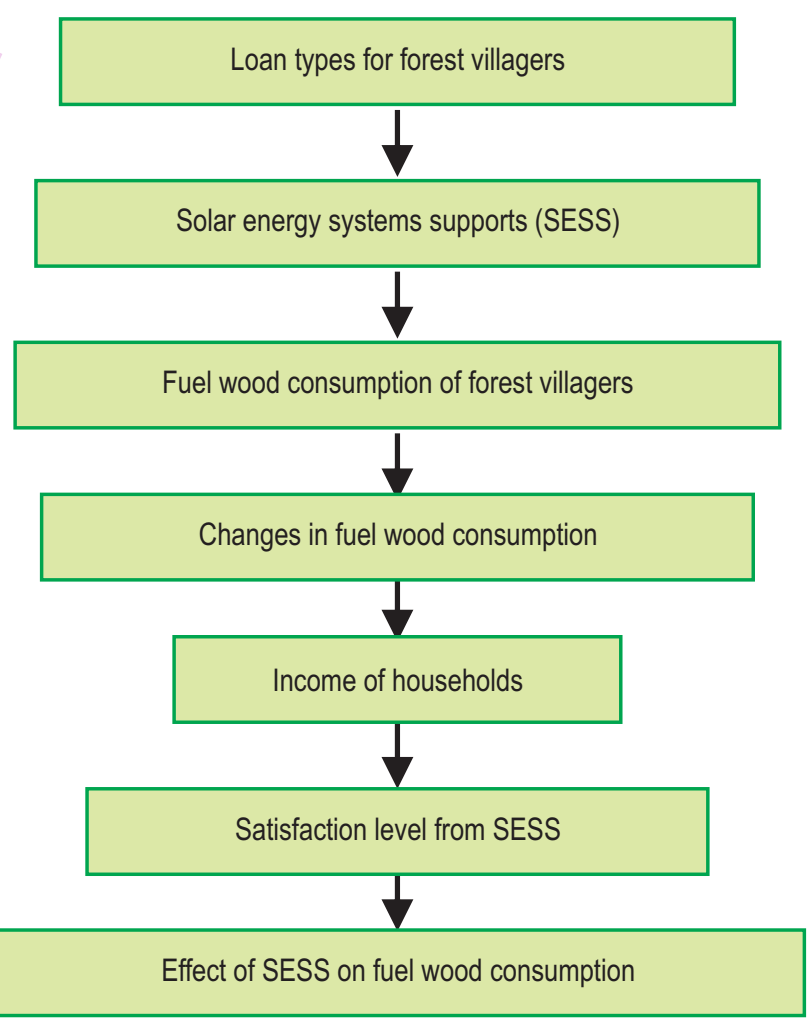




\section{Introduction}

The establishment of the General Directorate of Forest and Village Affairs (GDoFVA) and its provision of services is a reflection on the approach used by governments in power during the 1960 s for rural development. One of the ministries founded by the 28th Government, the Inonu Government in power between 1963-1965, was the Ministry of Village Affairs. With the transition to a planned system, the Ministry (established in 1963) carried out work targetted both rural sectors and forest villages. Together with the establishment of the GDoFVAin 1970, their activities were aimed at improving forest villages in terms of quality. Activities for the regulation of public-forest relations in particular found a niche in the forestry sector (Coşgun, 2008). This was strengthened with the establishment of the Ministry of Forestry in 1973 and the General Directorate of GDoFVA. During the past 45 years, the Ministry of Forestry and GDoFVAhas continued to carry out its responsibilities within various organizational structures. Today, departments of theGDoFVAcontinue to carry out its activities and responsibilities and GDoFVA is still providing social and economic support to forest villages by means of cooperative and individual loans.

The main function of GDoFVA is to regulate public-forest relations with the aim of reducing the pressure on forests by forest villagers. Since establishment, the organization has provided social and/or economic related support. Projects implemented as cooperative or individual loans have varied according to economic and political activities at national level. In the scope of this process, research conducted by Directorates of Forestry Research and the Forestry Faculties of universities (including other faculties), have sought to regulate public-forest relations, to determine the characteristics of rural communities, to assess the place of forest villagers in society and to ascertain socioeconomic conditions (Sakman, 1974; SPO, 1970; SPO, 1971). The organization of forest engineers has enabled these policies to be open for discussion by forest villagers and the activities of GDoFVA have been assessed in general terms with the aim of shedding light on the processes so far (CoFE, 1974). The early practices/activities of GDoFVA, up to the 1980s, have been reviewed and data has been produced that contributes to the field studies and actions of GDoFVA, on the basis of a variety of field studies (Anıl, 1973; Duruöz, 1975; Duruöz et al., 1976).

The second phase of GDoFVA took place in the 1980s. During this period, studies increased concerning forest villages, which were aimed at contributing to the activities of GDoFVA through research regarding urbanization and forest-village relationships. These were conducted by taking samples of the population within the scope of the socio-economic structures of forest villages,evaluating the development of forest villages and, with regard to the GDoFVA district development plans, research was conducted to determine the optimum enterprise plans by using linear programming techniques for the economic analysis of forest villages-agricultural enterprises for the districts (GerayandAcun, 1980; Acun, 1983; Taraklı, 1982). Important data for GDoFVA was ascertained, regarding the impact of energy consumption by forest villagers (Istanbullu, 1978). The 1960 1980 period was reviewed in an attempt to establish levels of Village, Town and City Social Transformation. By the end of the second phase of GDoFVA, the GDoFVA activities had been investigated and new GDoFVA models were being discussed, regarding activities for the development of forest villages and the future of GDoFVA(Akşit, 1985; Çağlar, 1986).

The third phase of GDoFVA was in the 1990s, where a variety of studies were conducted on the activities of GDoFVA. The socio-economic problems of forest villages were determined and recommendations for district or regional level solutions for the development of the forest villagers were advanced (Coşgun, 2005). The global concept of Social Forestry was discussed and new opportunities for GDoFVA were considered (Tolunay, 1992; Tolunayet al., 2007). During this period, investigations were made into the effects of the GDoFVA plans and the effect of their implementation on the forest villagers (Gümüş, 1993). In particular, the level of firewood used by forest villagers and its impact on both the forest eco-system and the socio-economic situation of forest villagers were determined. Through this, the GDoFVA practices were evaluated in a different light (Türker and Toksoy, 1992; Alkanet al., 205).

In the fourth phase of GDoFVA, two main areas of activity of GDoFVA were highlighted. The first of these was to establish the measures and criteria to be used in the scope of individual and cooperative loan provisions (Coşgun et al., 2007; Coşgun et al., 2009; Alkan, 2009; AlkanandDemir, 2013; Tolunayet al., 2002). The second area was evaluation of the impact on the forest villagers of the ORKÖY projects implemented to date (Tolunay and Korkmaz, 2005; Uzun, 2008;ÖnalandBekiroğlu, 2011; Ay andTolunay, 2012; Okutucuet al., 2012; KorkmazandAlkan, 2014). These studies also assessed the regional GDoFVA Solar Energy Systems (SES) practices.

With each passing day there is an ever-increasing demand for energy throughout the world, which serious concern of technical, economic, as well as ecological, problems. The International Atomic Energy Agency estimates that between the years 2005-2030 the world's energy demands will increase by $55 \%$ (IAEA 2015). The largest share of this increase will be $84 \%$ for fossil fuels; that is, oil, coal and natural gas. The rapid depletion of fossil fuels will not only lead to an energy crisis but also an ecological crisis. According to estimates from the World Bank, the commercial volume of the solar energy industry will be US $\$ 4$ trillion over the next 30 years. Turkey, a country poor in nonrenewable fossil fuels, is $70 \%$ dependent on foreign imports in terms of energy, costing billions of dollars each year; however, Turkey has high potential in terms of solar and wind (EIE SEPA, 2014). 
With regard to sunshine duration in the Mediterranean Region, Turkey ranks second in terms of longest sunshine duration. As a result, it is of ecological and economic importance for the forest villages to take advantage of the SES in this region. $A$ solar heated hot water system prevents the consumption of 11.4 barrel of petrol each year and ensures a saving equal to that of the fuel consumed by a medium sized sedan vehicle travelling 20.000 $\mathrm{km}$ in distance (CWG, 2013). With regard to renewable energy, Turkey has a potential of: i) 47,000 MW hydroelectricity (110-165 billion kWh/year electricity production), ii) 48,000 MW wind energy (120-130 billion kWh/year electricity production), iii) $31,500 \mathrm{MW}$ geothermal energy (this potential is suitable for the production of $600 \mathrm{MW}$ electricity), iv) 1,3 billion kWh/year biomass energy, v) solar energy with a potential of 930 billion kWh/year electricity (GDoSHW 2013; ElE REPA, 2007;ElE GEPA, 2010). The renewable energy sector is also important in terms of the opportunities it provides for employment and, in addition to economic and environmental benefits, it is also important in terms of social benefits. To opt for renewable energy investments creates potential for developing projects, construction-installation, management and maintenance, and repair processes. Furthermore, it creates employment and opportunities for skill development for manufacturing and human resources for machinery, materials and industry (YıImaz, 2014).

Estimates regarding developments in the energy sector, point to an increase in the share of renewable energy, leading to a parallel large-scale increase in employment in the sector. In the most comprehensive report regarding green energy, prepared by UNEP, ILO, IOE and ITUC, it is stated that there are expectations that by the year 2030, 12 million people will be employed in the sector related to agriculture and industry regarding biomass alone, 3.3 million will be employed in the solar energy sector and 1.2 million people will be employed in the wind energy sector (ILO, IOE, ITUC, 2008). There has also been planning and forecasts in Turkey concerning the level of employment in the renewable energy sector. According to different scenarios, the annual employment rate in the solar energy sector will be between 5,000 8,000 people/per annum. It is estimated that the rate of employment for the biomass energy production sector will be 800-1,300 persons/per annum (Yılmaz, 2014).

The contribution made to national development and the protection of natural resources by means of solar energy has gained international interest. The utilization of solar energy systems contributes to a reduction of approximately $70 \%$ in greenhouse gas emissions and energy savings. For example, in China and India are among the countries with the largest growth dynamics in terms of the widening of the market for solar energy systems. The most significant barrier in India is the problem of financing. Only low cost micro-loans are useful for reducing the problem (Menanteau, 2007). In China, the widespread efforts being made for water heating systems using solar energy has reduced the consumption of electricity and it is seen as a social project contributing to socially sustainable development (Wang, 2006). In Algeria, $40 \%$ of the fossil fuel produced in the country is consumed in the domestic market, and $98 \%$ of the national export. The most important funding for this kind of provision is state subsidy (Mouniret al, 2013). Following demands by the Albanian Government, since 2009 the UNDP and The Global Environment Facility (GEF) have begun to support an increase the solar energy water heating technologies. Within the scope of the project, by 2020 it is aimed to increase the size of the collecting area from $20,000 \mathrm{~m}^{2}$ to $520,000 \mathrm{~m}^{2}$ with cooperation from the UNDP and the Ministries of Economy, Trade and Energy and the Environment, Forestry and Water. By using solar energy instead of electricity, it is planned to reduce $\mathrm{CO}_{2}$ greenhouse gases by up to 800,000 tons, as a cumulative total, by the same year (UNDP, 2013).

Close to $12 \%$ of residential households in Jordan use solar energy systems to heat water. In a financial comparison of traditional water heating methods and solar energy systems, socio-economic evaluations present the losses and gains with regard to financial, social, cultural and ecological impact. Socioeconomic assessments are the most common method of analysis of cost-benefit. An Analytic Hierarchy for central heating (petroleum products), using LPG, kerosene, electricity and solar energy systems, found that the most inexpensive means of heating was solar water heating systems. Solar energy water heating systems are the most preferred system in Jordon (Mohesenand Akash, 1997).

\section{Materials and Methods}

The written resources related to this current study were obtained by survey literature and publications of the relevant public organizations and institutions. The unique data was obtained by administering a face-to-face questionnaire. The information regarding those forest villages, in the provinces of Antalya, Burdur and Isparta, where the solar energy system (SES) had been implemented was obtained from the GDoFVA Department of the Antalya and Isparta Regional Directorates of Forestry. Between the years 2005-2009, a total of 760 SES systems were put into service in 37 forest villages of Antalya. Between the years 2007-2010, a total of 1,330 SES were implemented in 50 villages in Burdur and in Isparta, and between 2008-2011, a total of 1,357 SES were established in 65 villages. $A$ total of 2,447 households received the SES systems, in 152 forest villages in the Western Mediterranean Region. By taking into account the numbers realized in each village, a formula (1) was used to determine how many villages should be included in the study sample (Miran, 2002). The variables of the formula are: $\mathrm{N}$ : population volume; t: standard normal distribution value $(\mathrm{P}=95 \%$ probability value of 1.96); $\mathrm{S}^{2}$ : Variance (S: only population volume standard deviation), $\bar{X}$ : Sub-population average, e: acceptable maximum error. 


$$
\mathrm{n}=\frac{S^{2} * t^{2} * N}{(N-1) * e^{2}+S^{2} * t^{2}}
$$

According to this formula, a sample was determined as 29 forest villages out of the 37 in Antalya, where the SES was implemented, 30 out of 50 forest villages in Burdur and 41 out of 65 forest villages in Isparta. In the Western Mediterranean Regions, 100 forest villages out of 152 have been included in the sample. In regards to how many enterprises in each village to be sampled was identified by selecting $15-20 \%$ of the total existing enterprises. Thus, it was determined that there would be 141 questionnaires administered in Antalya, 220 in Burdur and 226 questionnaires to be administered in Isparta. A total of 629 questionnaires were administered to a sample of $25.7 \%$ of the 2,447 families that had taken advantage of the SES. The data obtained was firstly evaluated using simple averages. In the second phase, normalization tests were carried out and ChiSquare analysis was conducted for the variables that did not show normal distribution. At this stage, a simple correlation was carried out to determine the degree and direction of the tests, in order to find the significant relationships. As the variables did not show a normal distribution and were non-parametric, a Spearman Correlation was conducted. To find out which variable was effective in the relationships, the Kruskal Wallis $\mathrm{H}$ was used, similar to the ANOVA test (SaruhanandÖzdemirci, 2005).

\section{Results and Discussion}

GDoFVA SES Practices in Turkey: From 2005 to 2013, GDoFVA provided Water Heating Systems with Solar Energy Loans. A loan value of 233,464 million TL was used (Anonymous, 2013-a).

Under the project heading, Reasons for Selection of the Project Capacity, the implementation document of the GDoFVA, Solar Energy System with Two Collector Fuel Storage Type, Project (social objective), it is emphasized that i) the annual firewood consumption of a kitchen stove is 10 stereand ii) the annual firewood consumption of a furnace is 25 stere, leading to a total firewood consumption of 35 stere. Under the same section of the document, it is stated: " 15 stere of a total of 35 stere of firewood is used for heating water, for use when bathing, washing clothes and dishes." As can be seen, a considerable amount of firewood saving could be foreseen with the implementation of the SES in forest villages (Anonymous, 2013-b). The study was conducted in the forest villages of Antalya, Burdur and Isparta provinces, within the Western Mediterranean Region and where the GDoFVA SES (Solar Energy System) was implemented. The objective of the study was investigate the results of reducing the consumption of firewood by heating water with the rapidly disseminating Solar Energy System (SES) which was launched in 2005 by GDoFVA.

The demographic structure of forest villagers taking advantage of the GDoFVA SES practices in the western

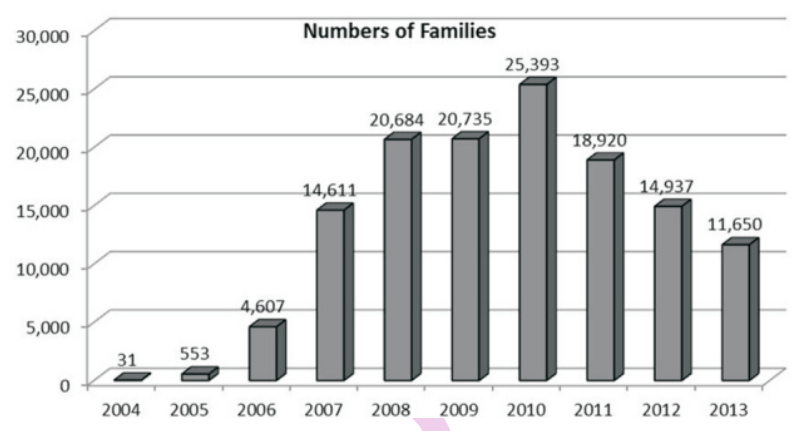

Fig. 1: Number of families obtained SES loans in consecutive years

mediterranean region : Of the sample used, $78.5 \%$ men and $21.5 \%$ women were heads of the households in the forest villages of the Western Mediterranean Region at the time of the study. Regarding the heads of household of the forest villages of the region, $22.0 \%$ were illiterate; $3.2 \%$ were literate; $83.8 \%$ were primary education graduates; $7.2 \%$ were middle school graduates; $3.2 \%$ were high school graduates and $0.5 \%$ were university graduates. A review of the distribution of age range of the head of households found that $82.7 \%$ were aged $15-64$ and $17.3 \%$ were aged $65+$. Of the heads of household in the study sample, $10.4 \%$ were found to be holders of a 'green card', $10.4 \%$ were registered with the Social Security Agency, $34.5 \%$ were registered as artisan/self-employed, $1.9 \%$ were included in the State retirement fund, $7.6 \%$ were part of another form of social security and $0.9 \%$ had no social security. The main source of livelihood of the households in the study sample were: $44.1 \%$ agriculture-farming, $17.2 \%$ livestock, $18.3 \%$ retired, $2.2 \%$ old age pension (for those aged $65+$ ), $15.3 \%$ laborers, $0.6 \%$ commerce/trade, $1.0 \%$ self-employed and $0.3 \%$ retired disabled.

The effects of the GDoFVA SES practices in the western mediterranean region on saving on wood : In the forest villages of the Western Mediterranean Region, $47.5 \%$ of the solar water heated is used for bathing, $50.3 \%$ is used in the kitchen and $2.3 \%$ is used in household cleaning. A review of the use of firewood by forest villager households showed that, in the scope of the ORKÖY SES practices, there was an increase of $78.8 \%$ in the use of firewood, a $3.5 \%$ increase in usage and $17.7 \%$ showed no change. It was found that the saving on firewood by households using the solar energy system in the forest villages in the Western Mediterranean Region was as follows: i) $47.4 \%$ "very little saving", ii) 24.2\% "little saving", iii) 20.1\% "medium level" saving, iv) $7.4 \%$ "high level of saving" and v) $1.0 \%$ "very high level of saving". In the region where the SES was implemented, the percentage of the group that stated that the amount of firewood saved was very little or little was $71.6 \%$. The percentage of the group that stated that they had a medium, high or very high level of saving was $28.5 \%$. It was seen that the realized firewood saving in the forest villages in the Western Mediterranean Region, 
where the SES had been implemented was 30.0\%. In the forest villages of the Istanbul District of Şile, where the GDoFVA SES was implemented, it was found that there was a $71.0 \%$ reduction in the use of cylinder LPG. A total of $52.0 \%$ reported that there was a reduction in electrical consumption and $13.0 \%$ stated that there was a reduction in consumption of firewood (Önal and Bekiroğlu, 2011). These findings support the proper assessment was done in the forest villages of the Western Mediterranean Region concluding $30.0 \%$ reduction in the consumption of firewood.

Economic contribution of GDoFVA SES practices in the western mediterranean region : The average wood consumption per household in the forest villages of the Western Mediterranean Region is 11.74 stere. Within the firewood amount used is also included the amount of firewood that the villagers receive from the forestry administration. In the study it was identified that the amount of firewood purchased for personal use by the villagers from the forestry administration is $11.1 \%$ for the region in general.Second type to supply is collection of wood material which are removal wood from in forest production area and wood in their garden. The net consumption is 10.437 stere $\left(11 \cdot 74^{*} 0,111=1.303\right.$ stere $\left.\cdot 11 \cdot 74-1 \cdot 273=10.437\right)$. In addition, we found SES contribution to annually firewood consumption. Estimated contribution of SES is 3,1311 stere $\left(10.437{ }^{*} 0,30=\right.$ $3,1311)$.

In a study conducted with forest villagers in the region for the Burdur District of Bucak, it was found that the annual firewood saving was 3,2004 stere following the implementation of the solar energy systems (Ay, 2011).

Assuming that one stere of firewood would be approximately $350 \mathrm{~kg}, 3,1311$ steres of firewood would be $350 * 3.1311=1.095,89 \mathrm{~kg}$ of firewood. It can be seen that a saving of 1.095,89 ton of firewood, or 3.1311 stere, will be saved per household in the forest villages of Western Mediterranean region. According to Islam (2015) this saving is 2978,4 ton annum ${ }^{-1}$ very high approximately more than twice that found by study. According to Ay (2011), this saving is $1,126.3 \mathrm{~kg}$; very close to that found by the study. In this sense, the findings of the two studies support each other and are consistent. Considering that the market price of one ton of firewood is an average of $300 \mathrm{TL} / \mathrm{ton}$, the use of a solar energy system will contribute an amount of $1.095,89^{*} 300=328,767 \mathrm{TL}$ per household, to the economy of the forest villager.

Taking into consideration the period of investigation (2005-2011), it can be seen that the forest village households $(3,447)$ taking advantage of the Western Mediterranean Region SES practices by using a total annual amount of 40,468 stere of firewood annually. Of this amount, $11.1 \%$ is used for personal purposes and is provided by the forestry administration. This amount is, $40,468^{*} 11.1 \%=4,491.948$ stere for personal consumption. The remaining, 40,468-4,4911.948=35,556.052 stere, is the annual consumption of firewood which is in addition to the firewood obtained from the forestry administration for personal use. Considering that a saving of $30.0 \%$ will be obtained through the utilization of SES in the forest villages of the region, the amount of the saving for the regional forestry institution by not consuming firewood will be $35,556.052^{*} 0,3=1,666.816$ stere. As one stere of coniferous wood is $350 \mathrm{~kg}, 10,666.816^{*} 350=$ $3,733.385 .600 \mathrm{~kg}$ of wood, that is, $3,733.4$ ton of firewood per annum will have been saved.

When considering the market price of firewood, the following can be said: as the market price of one ton of firewood on average is $300 \mathrm{TL}$, an annual contribution of 3,733 ton/year * $300 \mathrm{ton} / \mathrm{TL}=1,120$ thousand TL per ton/year will be made. On the other hand, within the period investigated, the 3,447 SES systems were implemented in a total of three provinces during 2005-2011. On average, a SES system is 1,200 TL, leading to a commercial investment volume of $3,447^{\star} 1,200=4,136.400 \mathrm{TL}$ in the region over a period of six or seven years. By using solar energy, the saving of LPG by the Western Mediterranean Region forest villages is $61.44 \%$. Assuming that they use four cylinders of LPG per year and that the cost of each cylinder is $75 \mathrm{TL}$, the annual cost of consumption of $L P G$ in forest villages is $75 * 4=300$ TL/year. By using the solar energy system, a saving of up to $60 \%$ will be gained, leading to a saving of $180 \mathrm{TL}$ per year per household.

Contribution made by GDoFVA SES practices in the western mediterranean region to the household budget: Households of the forest villages in the Western Mediterranean Region where the GDoFVA SES was implemented reported that the practice contributed to their household budgets as follows: i) $25.0 \%$, "very little" contribution; ii) $44.4 \%$, "little" contribution; iii) $18.1 \%$, "medium" level contribution; iv) 9.7\%, "high" level contribution and v) $2.9 \%$ "very high" contribution. The forest village households in the sample area of the study reported the following regarding their household costs regarding firewood: i) $14.9 \%$ reported that there was no contribution; ii) $36.2 \%$ reported that there was very little effect; iii) $22.1 \%$ reported that there was very little effect; iv) $22.3 \%$ reported that there was a medium level effect; v) $2.9 \%$ reported that there was a high contribution and vi) $1.6 \%$ informed there was a very high level contribution. Considering that $73.3 \%$ showed a low contribution to the household budget consumption for firewood by forest villagers, a discussion regarding the use of firewood in forests must be undertaken.

Level of satisfaction regarding the GDoFVA SES practices in the western mediterranean region : The forest villager households reported their levels of satisfaction as: i) $2.2 \%$ were satisfied "very little" by the implementation; ii) $1.0 \%$ were satisfied at a "low" level; iii) $6.4 \%$ were satisfied at a "medium" level; iv) $23.4 \%$ were "very" satisfied and v) $66.6 \%$ were satisfied at a "very high" level. A total of $90.0 \%$ of the villagers who have taken 
Table 1: Statistical significance by Chi square

\begin{tabular}{llll}
\hline & Chi-square tests & Asymp. Sig. (2-sided) \\
\hline Palue & df & .000 \\
Learson Chi-Square & 55.861 & 16 & .000 \\
Linelihood ratio & 43.810 & 16 & .093 \\
No. of valid cases & 2.818 & 1 & \\
\hline
\end{tabular}

Table 2 : Sperman'scorrelation test between the levels of contribution to the household budget and satisfaction level for the use of SES

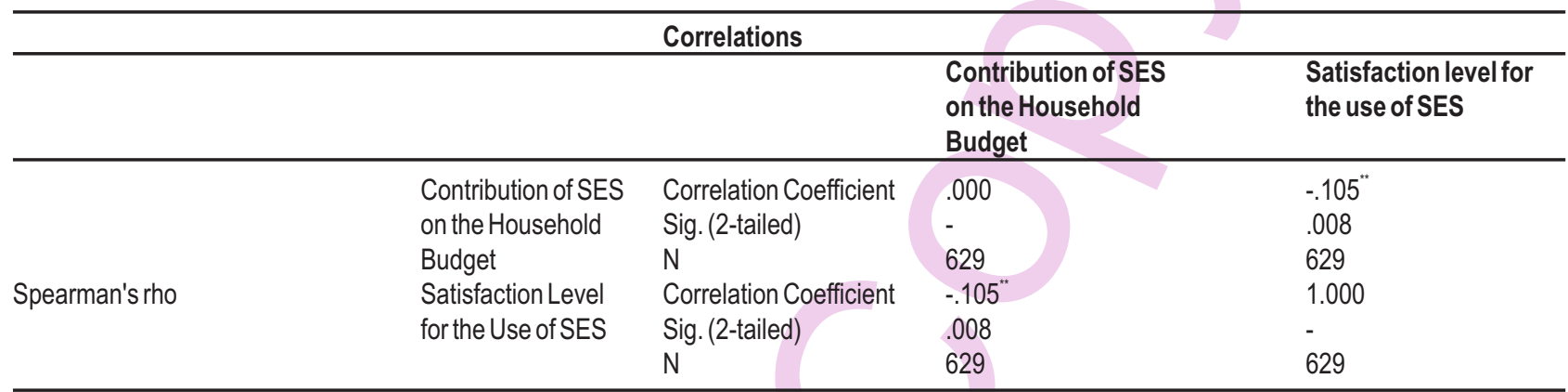

${ }^{* *}$. Correlation is significant at the 0.01 level (2-tailed)

Table 3 : Analysis of significance groups for relationship - groups

\begin{tabular}{llll}
\hline & Level of contribution to the household budget with the SES supports & N & Average \\
\hline Satisfaction level for SES Support & 1 "Very little" contribution & 157 & 320.69 \\
& 2 "Little" contribution & 279 & 336.09 \\
& 3 "medium level" contribution & 114 & 271.48 \\
& 4 "High level" contribution & 61 & 296.82 \\
& 5 "Very high level" contribution & 18 & 275.67 \\
& Total & 629 \\
\hline
\end{tabular}

advantage of the GDoFVA SES practices reported that they were satisfied to a high level by the SES. Within the scope of SES practices in the forest villages of Erzurum, $90.2 \%$ of those taking advantage of the SES practices reported that they were very satisfied (Okutucu, 2012). To have obtained similar results in other regions shows that the practice is beneficiary in general and has a positive impact on the lives of villagers. Forest villager households taking advantage of the GDoFVA SES support reported that they were satisfied for the following reasons: i) $14.3 \%$ due to the "contribution made to the household budget"; ii) $53.4 \%$ due to its contribution to "saving time during personal hygiene"; iii) $30.0 \%$ due to the "improvement in the quality of individual and family life" and iv) $2.2 \%$ due to "improvement of individual and family health". Study advocates that, of the forest village households taking advantage of the ORKÖY SES support, $4.5 \%$ were "wealthy families"; $54.1 \%$ were "middle class families" and $41.5 \%$ were "poor families."

Relationship between criteria regarding socio-economic structure of forest villagers who participated in the GDoFVA
SES practices in the western mediterranean region : The relationship between the various socio-economic variables regarding the forest villagers taking advantage of the GDoFVA support in the region was also investigated. Among these variables, for example, a relationship between the level of contribution made to the household budget and taking advantage of the SES support was found. There was also a relationship between the main source of livelihood of the population of the forest villagers and the population of enterprises. A relationship between the level of satisfaction of the SES support and the change in the level of consumption of firewood was also found. It was found that there was a relationship between the change in the level of consumption of firewood and the sources of the firewood consumed by the villages. A relationship was found between the level of contribution on the household budget and taking advantage of solar heat and having any kind of social security.

The statistical analysis of the relationship between the level of contribution to the household budget and level of 
satisfaction of the GDoFVA SES support is presented below. There was a relationship between the levels of contribution to the household budget of taking advantage of the SES support and satisfaction levels of the support by solar heat SES (Table 1). There is no statistically significant or negative relationship found between the general level of satisfaction by the forest village households and the solar heat support; however, the opinions of the households regarding whether solar heat contributed to the family budget is low. This situation can be seen as a statistically inverse relationship, and it is consistent with the results found for the questionnaire that can be seen in tabulated form in Table 2 .

The results of the test to determine which group is a parameter on the relationship between the contribution of the SES on the household budget and the level of satisfaction of the SES support showed that the highest ranking response for the level of contribution to the household budget, as a result of the SES support, was "little" and second ranked was "very little" as an impact on the level of satisfaction for the SES support (Table 3).

The study showed that the contribution of SES Project of GDoFVA to reduce the firewood consumption is not as big as the assumptions which were thought at the beginning of the project. However, the project carried out an essential contribution to reduce the firewood consumption in addition to the contribution to increase the rural life quality. Despite the expectation that the reduction of firewood consumption causes a contribution to the economy of household, it does not supply any contribution since the households have already used the harvesting remnants in the forests or dry twigs/logs, which does not make any cost for households. So, SES projects should be accepted as social projects increasing the life quality of forest villages by supplying high level of health and modern life standards rather than the economic contribution.

It was seen that SES projects were successfully implemented and disseminated throughout the forest villagers with the middle or lower socio-economic level and the project managers have met their objective with success. In addition to these successes, to decrease the firewood consumptions with higher levels, some other prevention can be proposed like insulation for the inner facades of the houses and kitchen stove with central heating. With these applications, it will be possible to heat the whole house in winter with only one stove burning at one location. This will bring a saving, as there are usually two stoves/heaters in the houses of forest villagers in winter.

It was seen that the approach of waiting for a demand from the villages, to implement the GDoFVA support, was not an effective method. Furthermore, the "kitchen stove with central heating" is a Project that comes at a high cost. GDoFVA provides grants for this project and this being the case, the project cannot become widespread, due to limited resources. Whereas, solar energy systems have an important place and role in the energy polices of countries, GDoFVA may be able to take advantage of international external resources, while supporting various energy saving projects. For example, the support of the UNDP and GEF may be sought (UNDP, 2013). It will be able to receive grant

support by developing the "kitchen stove central heating" project by emphasizing the current agenda items, such as supporting of the reduction of consumption of fossil fuels and reducing greenhouse gases. These contributions will be significantly reflected in the state economy. Examples of public policy regarding the use of energy through SES systems can be seen in countries like China, India, Albania, Jordon and Egypt (Menanteau, 2007; Mouniret al, 2013; Wang, 2006; UNDP, 2013; Mohesenand Akash, 1997).

It was also found that the SES systems in the Western Mediterranean region make a business of 4.1 million TL. It was found that the GDoFVA SES practice contributes more than just savings on firewood in the forest villages; there is a higher dimension of contribution, such as environmental and employment related aspects(Yılmaz, 2014).

\section{Acknowledgment}

This study was carried out under the project of Southwest Anatolia Forest Research Institute (Project No: 19.8206/20122013-2015).

\section{References}

Acun, E.: Studies on development of villagers in the province of aydın and especially Forest Villagers. Istanbul University Publication No: 3141, Forest Faculty Publication No: 338, Istanbul (1983).

Akşit, B.: Social Change in Villages, Towns and Cities. Turan Publishers, Ankara (1985).

Alkan, H., M. Korkmaz and A. Tolunay: Evaluation of Forest-Population Relations in Forestry Activities in the Province of Burdur, " $1{ }^{\text {st }}$ Burdur Symposium, Proceedings. Vol. I, pp. 16-19 November, Burdur (2005).

Alkan, H. and E. Demir: Factors which Impact on the Development of Cooperativism in Forest Villages, Süleyman Demirel University Journal, 14, pp.1-9 (2013).

Alkan, $H_{\text {.: }}$ Negative impact of rural settlements on natural resources in the protected areas: Kovada lake national park, Turkey. J. Environ. Biol., 30, 363-372 (2009).

Anıl, Y.: Socio-Economic Fabric of Yukarı Çulhalı Village. Institute of Forestry Research Technical Bulletin No: 57, Ankara (1973).

Anonymous: Data of General Directorate of Forestry, Department of GDoFVA, Ankara (2013-a).

Anonymous: Department of GDoFVA, Type Project for Two Collector Fuel Tank Solar Energy System (Social), Ankara (2013-b)

Ay, S. and A. Tolunay: Impact on Consumption of Firewood on the Household in regards to the Use of Solar Energy Heating Systems in Forest Villages. Third Congress for Socio-Economic Problems in Forestry", Istanbul(2012).

CoFE (Chamber of Forest Engineers): Union of Chambers of Turkish Engineers and Architects (UCOTEA), Chamber of Forest 
Engineers, Turkish Forest Engineering. Fifth Technical Congress on Forest-Village Relations in Regards to Regular Forests, Experts Views, pp. 48-61, Ankara (1974).

Coşgun, U.: Socio-economic Structure of Forest Villages of Western Black Sea Region and Determining the Effective Socio-Economic Factors impacting on these Villages by Means of Multi Quantitative Analysis Methods. Western Mediterranean Institute of Forestry Research Technical Bulletin No: 11, 2005, Bolu (2005).

Coşgun, U.: Western Mediterranean Directorate of Forestry Research. $50^{\text {th }}$ Anniversary "Proceedings"; Studies on Forest-Population Relations and Social Forestry. Ministry of Environment and Forest Publication No: 394, Publication of the Directorate No: 047, Antalya (2008).

Coşgun, U., Bekiroğlu, S. and A. Telek: "Determination of Forest Village's Prioritiesin Allocation of ORKÖY's Resources (Case Study: Antalya). Western Mediterranean Institute of Forestry Research Technical Bulletin No: 46, Antalya (2009).

Coşgun, U., H. Ok, E. Yılmaz, A. Telek, Z. Ay and E. Uzun: Findings of the Congress for Socio-Economic Problems in Forestry in Regards to Priorities of Forest Villages in the Allocation (2012).

CWG (Clean World Guide): Solar Energy Clean World Guide. Solar Energy. Clean World Ecology Association, Istanbul (2013).

GDoFVA Resources - Case Study of Antalya, Western Mediterranean Institute of Forestry Research Technical Bulletin No: 28, Antalya (2007).

Çağlar, Y.: Forest Villages in Turkey and Activities for Development, National Productivity Centre (NPC) Publication No: 340 , Ankara (1986).

Duruöz, E.: Research Studies on Contributions of Demirköy Forest Enterprise on Economic Structures of Forest Villages. Institute of Forestry Research Technical Bulletin Issue No: 61, Ankara(1975).

Duruöz, E., Anıl, Y. and C. Çoban: Employment Possibilities of Forest Villagers in State Forestry Activities and in Towns of Regional Forest Areas. Institute of Forestry Research Technical Bulletin Issue No: 79, Ankara (1976).

EIE REPA: Electrical Power Resources Survey and Development Administration. Wind-Power Energy Potential Atlas, Ankara(2007).

EIE GEPA: Electrical Power Resources Survey and Development Administration. SolarEnergy Potential Atlas, Ankara (2010).

EIE SEPA: Solar Energy Potential Atlas, Ankara, http://www.eie.gov.tr/ MyCalculator/Default.aspx; accessed, 25 November (2014).

GDoSHW (General Directorate of State Hydraulic Works): Written Interview, 1 February 2013, Ankara (2013)

Geray, U. and E. Acun: Urbanisation of Forest Villagers and ForestVillage Relations (Case of Safranbolu). Istanbul University Publication No: 2640, Forest Faculty Publication No: 279, Istanbul (1980).

Gümüş, C.: Opportunities for Benefiting from Multi-Dimensional Analyses of Forest Villages Development Plans and Social Forestry Studies. First Forestry Summit, Notices and Reports of Works Groups", Vol. II, pp.267-278 (1993).

IAEA (International Atomic Energy Agenciy: https://www.iaea.org, accessed (2016).

ILO/IOE/ITUC. Green Jobs: Towards Decent Work in a sustainable, LowCarbon World, United Nations Environment Programme, Nairobi, September (2008).

Islam, M., A., S.M.S. Quli, R. Rail, A. Ali, and S.A. Gangoo: Forest biomass flow for fuel wood, fodder and timber security among tribal communities of Jharkhand. J. Environ. Biol., 36, 221-228, India (2015)

Istanbullu, T:: Studies on Issues Regarding Fuel and Especially Firewood in Turkey. Istanbul University Publication No. 2405, Forest Faculty. Publication No: 251, Istanbul(1978).

Korkmaz, M. and H. Alkan: Forestry and Rural Development: Evaluation by Case Study of Forest Villages in Isparta. $2^{\text {nd }}$ National Mediterranean Forest and Environment Symposium, Proceedings Book, Isparta p.1084 (2014).

Menanteau, P.: Policy measures to support solar water heating: information, incentives and regulations, World Energy Council, "WEC ADEME project on energy efficiency policies",ADEME Project on energy efficiency policies, pp. 4-7, Université de Grenoble(2007).

Miran, B.: Basic Statistics, ISBN: 975-93088-0-0, Ege University Publ, İzmir, p. 278,(2002).

Mohesen, M. S. and B. A. Akash: Evaluation of domestic solar water heating system in Jordan using analytic hierarchy process. Energy Convers. Manag., 38, pp. 1815-1822 (1997).

Mounir, A., Zouagri, R. and A. Naamane: Technical-economic analysis of solar water heating systems at Batna in Algeria. In: Sustainable in Energy and Buildings SIST, Berlin, 22, pp. 787-796 (2013).

Okutucu, M.A., M. Demir, C. Agyürek, A. Bilgili and M. Güven: Research study of results of the gdofva projects implemented regarding solar energy as a source of renewable energy. $3^{\text {rd }}$ Congress for SocioEconomic Problems in Forestry, Istanbul (2012).

Önal, P. and S. Bekiroğlu: Research study of results of the GDoFVA village development projects implemented in forest villages, Istanbul University. Faculty of Forestry J., 61, 53-66 (2011).

Sakman, E.: Regulating forest village relations. Turkish Association of Chambers of Agriculture Publication No: 99, Ankara (1974).

Saruhan, Ş. C. and A. Özdemirci: Science. Philosophy and Methodology. Beta Publications, ISBN 978-605-377-499-0, Istanbul (2005).

SPO (State Planning Organisation): Research Report on Trends of Modernisation in Turkish Villages. Report I, No: DPT: 860, SPD: 198, Ankara (1970).

SPO (State Planning Organisation): Research Report on Trends of Modernisation in Turkish Villages. Report III, Publication No: DPT: 1071, SPD: 233, Ankara (1971).

Taraklı, D.: Forest Villages of Mudurnu District (Economic analysis of agricultural enterprises and determining the optimum management plan for the district with the linear programming Method), Ankara(1982).

Tolunay, A.: Importance of Social Forestry and the Desired GDoFVA. Ministry of Forestry J., 1-5, 14-19 (1992).

Tolunay, A., M. Korkmaz and H. Alkan: Project evaluation criteria for preparing ORKÖY development projects. Rural Environment Almanac 2002, Ankara, pp.117-134 (2002).

Tolunay, A. and M. Korkmaz: $35^{\text {th }}$ Anniversary of GDoFVA. $1^{\text {st }}$ Environment and Forestry Summit, Notices and Reports of Works Groups, Antalya, pp. 1575-1582 (2005).

Tolunay, A., H. Alkan, M. Korkmaz and F.S. Bilgin: Classification of traditional agroforestry practices in Turkey. Inter. J. Nat. Eng. Sci., $1,41-48$ (2007).

Türker, M.F. and D. Toksoy: Solutions to the Problem of consumption of timber of state forests as firewood. Çevre J., p. 5-8 (1992).

UNDP. The Country program of albania under the global market transformation and strengthening initiative, Ankara (2013).

Uzun, E.: Determination of Socio-Economic Structures of Villages and 
Farm Holding Located in the Forests in Gündoğmuş County. Technical Bulletin No: 32, Antalya (2008).

Yılmaz, S.A.: Green Jobs and Their Potential in Renewable Energy in Turkey, Ministry of Development, General Directorate of Social
Sectors and Coordination, Publication No: 2887, Ankara (2014). Wang, Y. and L. Zhao: Economic analysis of solar water heater in Guang Zhou: Policy for energy efficiency and comfort. Vol.VII-4-4, China (2006). 